\title{
MUNDO, DEMONIO Y CARNE. PROCESO DE SECULARIZACIÓN, FEMINIZACIÓN DE LA RELIGIÓN Y SOCIABILISMO CATÓLICO EN LA DIÓCESIS DE TARRAGONA (1932)
}

\author{
WORLD, DEVIL AND FLESH. THE PROCESS OF \\ SECULARIZATION, FEMINIZATION OF RELIGION AND \\ CATHOLIC SOCIABILITY IN THE DIOCESE OF TARRAGONA
}

(1932)

\author{
Monserrat DUCH PLANA \\ URV-Tarragona
}

Recibido: 30/07/2016

Aceptado: 14/11/2016

Para citar este artículo / To cite this article:

Duch Plana, Montserrat. «Mundo, Demonio y Carne. Proceso de secularización, feminización de la religión y sociabilismo católico en la diócesis de Tarragona». En Nieves Montesinos Sánchez y Beatriz Souto Galván (coords.), Laicidad y creencias. Feminismo/s, 28 (diciembre 2016): 269-292, DOI: 10.14198/fem.2016.28.11

Para enlazar con este artículo / To link to this article:

http://dx.doi.org/10.14198/fem.2016.28.11

\section{Resumen}

El proceso de feminización del catolicismo en España se profundizó en la segunda y tercera década del siglo XX en el marco de la política de masas, de la configuración de las mujeres como sujetos políticos y del impulso hacia la recristianización adoptado por la Iglesia. En este trabajo, a partir del análisis de las Estadísticas de la diócesis de Tarragona realizadas durante el arzobispado de Francesc Vidal i Barraquer (19221943), se corrobora el dimorfismo sexual o diferenciación creciente del comportamiento religioso entre hombres y mujeres que la sociología ha tematizado. Evidencias 
que proceden de una mayor prevalencia en la práctica prescrita y en las iniciativas de piedad. Asimismo, las mujeres son mayoría en la proporción de cuadros de la Iglesia esencialmente a partir del aumento de órdenes terciarias y de congregaciones femeninas, sean éstas contemplativas o activas dedicadas a tareas de cuidado (personas enfermas, infancia, pobreza). Las mujeres participaron en espacios de sociabilidad católicos que experimentaron un proceso de politización creciente durante la II República.

Palabras clave: secularización, laicismo, feminización de la religión, relaciones de género, sociabilidad católica.

\begin{abstract}
The process of feminizing Catholicism in Spain acquired greater importance in the second and third decade of the $20^{\text {th }}$ century in a context of mass politics, the configuration of women as political subjects and the drive by the Church towards re-Christianization. In this study, the analysis of statistics from the diocese of Tarragona drawn up when Francesc Vidal i Barraquer was archbishop (1922-1943) confirms the sexual dimorphism or increasing differentiation of religious behavior between men and women that has been discussed by sociology. The evidence shows that women engaged more than men in prescribed worship and pious actions. Likewise, women were a majority in Church groups, essentially after the increase in tertiary orders and female congregations, whether these were contemplative or actively concerned with caring (the ill, the young and the poor). Women were involved in centres of Catholic sociability, which underwent a process of increasing politicization during the $2^{\text {nd }}$ Republic.
\end{abstract}

Keywords: Secularization, secularism, feminization of religion, gender relations, Catholic sociability. 


\section{SECULARIZACIÓN EN CATALUÑA. FUENTES Y METODOLOGIA}

Una definición sintética de la tesis de la secularización remite al «proceso por el que la conciencia, las actividades y las instituciones religiosas pierden relevancia social» (Eliade 163) que se acompaña de dos subtesis: la socialización, o destrucción de las antiguas comunidades de creyentes, y la de la emancipación de las estructuras laicas respecto de los poderes sacros. En este ensayo, a partir del análisis de las Estadísticas de la diócesis de Tarragona realizadas durante el arzobispado de Francesc Vidal i Barraquer (1922-1947), me propongo analizar el grado de secularización que se observa en las parroquias y más concretamente la refutación o corroboración del dimorfismo sexual en el catolicismo de las primeras décadas del siglo XX en una diócesis catalana.

Un estudio de caso como el que se presenta a partir de la accesibilidad a una fuente extraordinaria de una diócesis singular regida por el arzobispo Vidal i Barraquer, protagonista de las relaciones Iglesia-Estado durante la II República. El análisis en perspectiva de género aporta ejemplos significativos de diversas parroquias catalanas en el contexto de la denominada «secularización conflictiva» (De la Cueva y Montero) con la concurrencia de dinámicas tendentes a la transición entre un vínculo fundamentado en la obligación a otro basado en el contrato (Marramao 23). La II República comenzó su andadura entre patentes muestras de fervor popular, como sostuviera Juliá, «de la fiesta popular a la lucha de clases». Sin embargo, los rituales celebrativos de su proclamación no se revolvieron, en principio, contra una de las instituciones más firmemente identificadas con el régimen monárquico cuya caída se festejaba: la Iglesia. Un importante sector de la jerarquía católica, encabezado por el nuncio Tedeschini y el cardenal Vidal i Barraquer, sabía que, con la República, la secularización del Estado se había de producir y confiaba en que las armas de la negociación y la mesura habían de rendir mejores frutos para la Iglesia que las del conflicto y el hostigamiento. (De la Cueva 2001, 259-260).

El anuario estadístico de 1931 sitúa en 4.220 personas el clero diocesano de Tarragona, 5 arciprestes, 151 parroquias, 17 filiales y 228 capillas-santuarios u oratorios. Las casas de religiosas de la diócesis eran 13 masculinas y 68 femeninas, con un total de 127 y 570 religiosos/as, respectivamente (Duch 1994, 136). 
Francisco Vidal i Barraquer, (1868-1943), arzobispo de Tarragona entre 1921 y 1943 emprendió una notable modernización de la acción pastoral mediante un análisis de las parroquias previas a las visitas denominadas ad limina - que los obispos realizaban cada cinco años al Papado- en los años 1922, 1927 y 1932. La encuesta era un método de vanguardia del catolicismo social europeo de aquel tiempo que, con otro formato, se realizó en otras diócesis como la de Vitoria (Rivera y de la Fuente).

El carácter del clero diocesano participa globalmente de una lógica defensiva en la estela de la «descristianización de la sociedad y reacción católica» (Montalbán). Los orígenes sociales de los seminaristas de la provincia eclesiástica de Tarragona en los años treinta eran predominantemente rurales, en un $54,4 \%$ poco útiles para los sacerdotes designados a parroquias urbanas socialmente complejas. Solamente un 7,3\% procedían de clases medias (profesorado, profesiones liberales o funcionarios) mientras que las clases altas $(0,81)$ y la nobleza $(0,1)$ eran irrelevantes en su composición sociológica (Callagan 169). Esta caracterización nos parece extensible a los párrocos, informantes de la situación religiosa de las parroquias que analizaremos en la doble dimensión cuantitativa sobre la feminización de la religión y cualitativa en los indicios de secularización.

El cuestionario impreso constaba de treinta y un capítulos que se fragmen$\tan$ a su vez en diferentes subpreguntas ${ }^{1}$. Estas se modificaron en 1927 y 1932, respondiendo a las diferentes necesidades e inquietudes de cada periodo. La recogida de información sobre los hábitos religiosos y de la vida cotidiana que contiene el cuestionario muestra la centralidad del cura, que en los núcleos rurales disponía de una posición de autoridad en la red de relaciones. «Las actitudes del clero eran asimismo plurales en el marco del catolicismo catalán de preguerra que está caracterizado por su catalanidad, romanidad y un cierto "nacional catolicismo", la veneración a Torras i Bages, vitalidad, conservadurismo moderado e indigencia teológica» (Duch 1997, 261-262).

En la Europa contemporánea se observa la disminución de la práctica religiosa, en una Iglesia que era cada vez más ajena a la cultura de las clases populares urbanas. También en Cataluña, en los años treinta, un estudio de la Federació de Joves Cristians indicaba que solo el $5 \%$ de la juventud podía definirse como católica al final de su escolarización. En el medio rural el cambio no fue tan evidente y parecía que era el marco más adecuado para la acción eclesiástica, ya que la vida parroquial y la vida cotidiana estaban estrechamente

1. Las encuestas se pueden consultar en el Archivo Histórico Archidiocesano de Tarragona (AHAT) La encuesta de 1922, del mismo modo que la de 1927, esta encuadernada y consta de cuatro volúmenes. La de 1932 consta de 140 unidades. 
ligadas eran, por tanto, espacios de socialización (Duch 1997, 264) en las que la mujer es considerada un puntal del catolicismo, por su mayor fidelidad a las doctrinas y normas eclesiásticas (Moreno 63).

\section{FEMINIZACIÓN DE LA RELIGIÓN}

El proceso de feminización del catolicismo alcanzó un significado político en el marco de la política de masas, de la configuración de las mujeres como sujetos políticos y del impulso hacia la recristianización (Blasco 120). En este trabajo se muestra como las estadísticas diocesanas de Tarragona corroboran el dimorfismo sexual o diferenciación creciente del comportamiento religioso entre hombres y mujeres que la sociología ha tematizado (Langlois, Gibson). Evidencias que proceden, como veremos, de una mayor prevalencia en la práctica prescrita y en las iniciativas de piedad. Asimismo, las mujeres son mayoría en la proporción de cuadros de la Iglesia esencialmente en el aumento de órdenes terciarias y de congregaciones femeninas sean estas contemplativas o activas dedicadas a tareas de cuidado (personas enfermas, infancia, pobreza) además de ligas y cofradías integradas por mujeres.

El proceso de feminización de la religión se manifiesta en un creciente protagonismo de las mujeres en el sector servicios, realizando tareas de cuidado a personas y enseñanza, que situaba el conjunto del clero femenino en la España de 1900 en el 44,8\%, que pasó al 52,9\% en 1930, mientras que en Cataluña la evolución va del $54,2 \%$ al $54,9 \%$ y en Tarragona provincia del $56,6 \%$ al $60,5 \%$. (Nash y Borderías, 174). Una dimensión relevante de la feminización del catolicismo, de la asociación simbólica de las mujeres con la religión que en el caso francés ha sido interpretado como dos polaridades opuestas: por un lado «lo político», espacio secularizado y masculino y, por otra parte, «lo religioso», asociado con lo privado y lo femenino (Blasco 122). Una actitud que se relaciona con la base del republicanismo que defendía la condición de individuos iguales, libres y autónomos para los hombres mientras que las mujeres eran definidas en tanto que sujetas a diferentes autoridades e inferiores. En segundo lugar, se ha demostrado una repulsa masculina al control de las mujeres por el clero así como, tercera causa, el rechazo por el clero de modos de sociabilidad masculina junto a la conversión de la Iglesia en centro de sociabilidad femenina. Finalmente, la existencia de una afinidad de naturaleza entre mujeres y religión, en el marco de una diferenciación cultural mayor que asociaba lo femenino con los roles afectivos, espirituales y religiosos; dialéctica de papeles sociales y relaciones de género a las que la Iglesia contribuyó en gran medida (Blasco 123). Así, en la construcción cultural de la masculinidad y de la feminidad destacan atribuciones diferenciales en relación con la religión y 
la espiritualidad «a medida que la indiferencia religiosa y el alejamiento de la Iglesia se convertían en atributo naturalizado de la masculinidad, una mayor religiosidad iba constituyendo la feminidad decimonónica» (Blasco 123). Se trata, por todo ello, de una cuestión esencial en la construcción de los papeles sociales de género a partir de los rendimientos emocionales obtenidos por las mujeres en sus prácticas de sociabilidad católica que experimentaban pulsiones de cambio en una sociedad que durante la II República transitó hacia políticas laicistas que alimentaron el conflicto religioso.

El carácter político del proceso de feminización del catolicismo en la Europa meridional, «más allá de contribuir a orientar las opciones de las mujeres de entrar en un convento o ir más a misa, modeló la actitud política de la Iglesia que complicó la tarea de las feministas, enfrentadas a una asociación de las mujeres con una religión que simbolizaba lo tradicional, el pasado y el conservadurismo» (Blasco 125). Una visión ecléctica a partir de los análisis de Gibson, Langlois y McMillan sobre este proceso supone considerar aspectos explicativos de la feminización tanto de la entrada de las mujeres en los conventos como del diformismo sexual en motivaciones individuales como la realización de ambiciones de tener carrera (las monjas), el acceso a una sociabilidad legítima y respetable (las laicas) así como otros beneficios emocionales mediante la búsqueda de escucha del clero.

La religión proporciona una teoría sobre la sexualidad y la reproducción humana que sitúa al hombre en el centro del proceso y determina que la feminidad se construya sobre los paradigmas de la complementariedad, la antítesis y la subordinación en contribución de los monoteísmos a la legitimación de la cultura patriarcal. En el catolicismo se forjará una idea de mujer basado en la figura de la María, virgen, esposa y madre, que se contrapone a la imagen de Eva y se convierte en el modelo virtuoso perfecto de feminidad (Warner). El objeto de la Asociación de jóvenes vírgenes por solteras, Hijas de María de la Santísima Inmaculada ${ }^{2}$, «reina de las vírgenes» se proponía «tributar un culto constante en la tierra a María Santísima, imitarla en sus virtudes, especialmente en la pureza de alma y cuerpo»; se organizaba sobre la base de coros de treinta asociadas con secciones de a diez mujeres. Era requisito para pertenecer a la asociación el estado civil de soltera y una conducta «verdaderamente cristiana». Como en toda organización católica la dirección era asumida por un «presbítero instruido y celoso» quien «autoriza la admisión de aspirantes» que decide la junta directiva integrada por mujeres en un espacio de experiencia

2. Estatutos. Fundada en Barcelona 7 de julio de 1850. Barcelona: Imprenta Heredero de Pablo Riera, 1865. 
y aprendizaje. En el libro de socias se hacía constar «si la salida sea por tomar otro estado». Sus principales actividades consistían en cuidar la imagen de la titular y guardar sus alhajas, vestidos y adornos y demás efectos que pertenecen a la imagen así como cuidar del adorno y aseo e iluminación de la capilla. Las obligaciones de las asociadas fijadas en los estatutos consistían en visitar una vez al mes a la Virgen en el día establecido, recibir los santos sacramentos de confesión y comunión, asistir a ejercicios religiosos «con la puntualidad que permitan las atenciones de casa, o la deferencia debida a los padres o mayores» así como «observar lo que se recomienda en la patente acerca de la pureza del lenguaje y cautela en la guarda de los sentidos», rezar todos los días tres avemarías, la oración y jaculatoria y participar en los sufragios por las asociadas difuntas, reunir limosna de las mesas o satisfacer la cuota.

En la diócesis de Tarragona la Archicofradía de Hijas de María contaba con escuela dominical preparatoria de la primera comunión de niñas a cargo de «señoritas instructoras y personas protectoras». En junio de 1924, por ejemplo, se celebraba misa de comunión cantando el Coro de señoritas «escogidas letrillas» por la mañana mientras que por la tarde Rosario, Salve cantada, Trisagio cantado por el Coro de la Escuela dominical y sermón que concluye con la «renovación de las promesas del Bautismo y canto final». En su calendario anual el mes de mayo, Mes de María, tenía una significación especial, así todos los días «rezo del Santo Rosario, Salve cantada, ejercicio del mes de María con el canto de las Ave-Marías, poesías a la Virgen por las niñas». Los festivos los padres Capuchinos platicaban sobre «las grandezas y glorias de la Virgen María». En la fiesta de la Ascensión, terminado el sermón, «se hará el descenso de la Imagen de la Virgen, ofrecimiento de flores, besamanos y canto de hermosas y variadas letrillas». En los solemnes cultos de la Archicofradía ${ }^{3}$ en mayo de 1926 el impreso hacía constar que «Se recuerda a los padres de familia y a las señoras Directoras, encargadas de acompañar niñas que, por la santidad del templo y el honor de la mujer: está prohibida la entrada a las niñas menores de doce años, si su vestido no cubre por lo menos hasta las rodillas; y más debajo de las rodillas después de los doce años».

Pio IX publicó el «Syllabus» con la encíclica Quanta cura, del 8 de diciembre de 1864, con el objetivo de condenar el liberalismo; diez años atrás, el 8 de diciembre de 1854, en un ritual al extremo patriarcal, rodeado en Roma por 54 cardenales, 46 arzobispos y 97 obispos, definió solemnemente el dogma de la Inmaculada, proclamando que María desde el primer instante de su concepción fue preservada inmune de toda mancha de culpa original. La devoción a

3. AHAT. Congregaciones. Hijas de María (1870-1945).

Feminismo/s 28, diciembre 2016, pp. 269-292 
la Inmaculada se expandió después de la aparición en Lourdes (1858) con la creación de numerosas congregaciones religiosas y asociaciones piadosas bajo su advocación. La solemne proclamación dogmática de la Asunción de María en cuerpo y alma a los cielos en 1950 así como la devoción al Corazón de María que cobró nuevo auge después de las apariciones de Fátima (1917). En 1950 se instituyó el dogma de fe la Asunción de la Santísima Virgen en cuerpo y alma a los cielos (Montalbán 432, 807, 853).

Es conveniente analizar la «identidad» de la Hija de María ya que, como veremos, se trata de una organización católica muy extendida en la diócesis, en el conjunto de Cataluña y de España. Tuvo una importante expansión a partir de la definición dogmática de la Inmaculada Concepción, «Reina de los Cielos y madre de Dios» a quien se tributará «un culto constante en la tierra». En imitación de las virtudes de la Virgen, especialmente en la pureza de alma y cuerpo, se recomendaba: 1.- «Usar siempre un lenguaje puro y honesto; guardarse de tener o escuchar conversaciones indecorosas y de pronunciar palabras equívocas o de mal sentido y apartarse de todo objeto o persona que pueda hacer peligrar la virtud»; 2. «Comunicar solo con amigas buenas y educadas, y no con aquellas que no tienen sentimientos religiosos, que son o se llaman despreocupadas; huir de las que murmuran y critican, de las que no saben más que de modas, cines, etc.»; 3.- «Vestir según la posición de su familia, sin lujo excesivo, y más que todo con modestia, desechando toda moda indecente o libre» y 4.- «Ejercitarse en la obediencia y respeto a los padres y superiores; en la amabilidad, buen trato y educación con las iguales y en la caridad y paciencia con todos, especialmente con las inferiores»; un compendio, en definitiva, de creencias y actitudes congruentes con el discurso de la domesticidad.

Hacía siglos que la teología católica debatía sobre la piedad ultramontana que adoptó la forma de una ofensiva a favor de tomar la comunión con frecuencia ante los rigoristas teológicos que argumentaban que el sacramento solo debía recibirse en estado de total arrepentimiento, y, por tanto, de manera infrecuente, Pio X puso fin al debate en 1905 al instar a los fieles a comulgar con frecuencia. A los ojos de los sacerdotes, el número de comuniones era un testimonio más del compromiso religioso de la población (Callahan 204). La comunión frecuente llevaba consigo la necesidad de confesarse de forma periódica, obligación que encontraba mucha resistencia. Los supuestos abusos del confesionario se convirtieron en parte habitual del repertorio de las abundantes publicaciones anticlericales que criticaban duramente la influencia de la Iglesia en la sociedad en el doble plano de control de la sexualidad y la influencia política. La resistencia a la confesión tenía raíces profundas también por la aversión 
a perder la poca privacidad en una comunidad rural cerrada y las suspicacias que despertaban los párrocos por el hecho de confesar a las mujeres.

La metodología utilizada en esta investigación ha consistido en rastrear el proceso de secularización y feminización del catolicismo a partir de la pregunta de William Callahan « ¿Acaso no había una contradicción fundamental entre el increíble número de devociones y de asociaciones piadosas y un enorme absentismo religioso en España? Los recargados vestidos que se ponían a las imágenes, la perpetua ronda de novenas y otros oficios devocionales, la dependencia respecto de multitud de símbolos externos, escapularios y medallas estaban concebidos para convertir el catolicismo español en "patrimonio casi totalmente de mujeres» (214). El vaciado exhaustivo de las encuestas correspondientes a treinta parroquias constituye una muestra representativa de la diócesis de Tarragona atendiendo a criterios de hábitat rural y urbano y a la dimensión de las parroquias. Como podemos observar en la tabla sobre observancia religiosa, solamente un exiguo 1,2\% participa diariamente del sacramento de la comunión, que tampoco supera el 7\% de quienes lo reciben con frecuencia. Las mujeres suponen el 92\% y el $85 \%$ respectivamente de los fieles que se acercan a comulgar.

\begin{tabular}{|l|c|c|c|c|c|}
\hline \multicolumn{5}{|c|}{ OBSERVANCIA RELIGIOSA. DIOCESIS DE TARRAGONA (1932) } \\
\hline Parroqua & $\begin{array}{c}\text { Población } \\
>7 \text { años }\end{array}$ & $\begin{array}{c}\text { Comunión } \\
\text { diaria } \\
\text { hombres }\end{array}$ & $\begin{array}{c}\text { Comunión } \\
\text { diaria } \\
\text { mujeres }\end{array}$ & $\begin{array}{c}\text { Comunión } \\
\text { frecuente } \\
\text { hombres }\end{array}$ & $\begin{array}{c}\text { Comunión } \\
\text { frecuente } \\
\text { mujeres }\end{array}$ \\
\hline Alcover & 2.643 & 1 & 15 & 8 & 130 \\
\hline Alió & 470 & 6 & 1 & 6 & 5 \\
\hline Botarell & 305 & 0 & 12 & 6 & 25 \\
\hline Cambrils (San Pedro) & 1.090 & 0 & 6 & 10 & 50 \\
\hline Cambrils (Santa María) & 1.836 & 2 & 30 & 20 & 125 \\
\hline Catllar, El & 1.146 & 0 & 12 & 10 & 30 \\
\hline Constantí & 2.058 & 0 & 35 & 11 & 100 \\
\hline Montbrió & 1.025 & 1 & 30 & 30 & 125 \\
\hline Morell, El & 1.609 & 0 & 70 & 25 & 250 \\
\hline Pont d'Armentera, El & 1.001 & 0 & 6 & 8 & 40 \\
\hline Reus (San Francisco) & 5.682 & 5 & 45 & 40 & 160 \\
\hline Reus (San Juan Bautista) & 4.430 & 10 & 80 & 80 & 500 \\
\hline Riudoms & 3.228 & 0 & 25 & 15 & 40 \\
\hline Roda de Bará & 591 & 0 & 8 & 6 & 30 \\
\hline
\end{tabular}




\begin{tabular}{|l|c|c|c|c|c|}
\hline Selva del Camp, La & 2.891 & 2 & 35 & 12 & 200 \\
\hline $\begin{array}{l}\text { Tarragona (San Juan } \\
\text { Bautista) }\end{array}$ & 10.670 & 12 & 85 & 50 & 300 \\
\hline $\begin{array}{l}\text { Valls (San António } \\
\text { Abad) }\end{array}$ & 1.738 & 2 & 28 & 5 & 20 \\
\hline Valls (San Juan Bautista) & 10.670 & 12 & 80 & 200 & 1.000 \\
\hline Total & 53.083 & 53 & 603 & 542 & 3.130 \\
\hline
\end{tabular}

Fuente: AHAT. Estadística Diocesana, 1932. Elaboración propia.

La opinión clerical llevaba tiempo observando con inquietud los efectos de la urbanización en la práctica religiosa. Ya, a finales de 1850, un párroco de Barcelona apreció que sólo un tercio de sus feligreses cumplían con su obligación de comulgar por Pascua. Los estudios sobre los niveles de observancia en España han mostrado el alejamiento casi total de la religión entre las clases bajas urbanas aunque se mantuvieran, como así indican las estadísticas de la diócesis de Tarragona, el bautismo y los matrimonios canónicos. El debate sobre el grado de ruralización del catolicismo se muestra en el caso de Tarragona destacando los municipios medianos en indicios de religiosidad y feminización del culto.

\begin{tabular}{|l|c|c|c|c|}
\hline $\begin{array}{c}\text { Tamaño de la } \\
\text { parroquia }\end{array}$ & $\begin{array}{c}\text { \% comunión } \\
\text { diaria } \\
\text { mujeres }\end{array}$ & $\begin{array}{c}\text { \% comunión } \\
\text { frecuente } \\
\text { mujeres }\end{array}$ & $\begin{array}{c}\% \text { comunión } \\
\text { diaria } \\
\text { mujeres y } \\
\text { hombres }\end{array}$ & $\begin{array}{c}\% \text { comunión } \\
\text { frecuente } \\
\text { mujeres y } \\
\text { hombres }\end{array}$ \\
\hline$>5.000$ & $88 \%$ & $83 \%$ & $0,9 \%$ & $6,5 \%$ \\
\hline 1.500 a 5.000 & $95 \%$ & $89 \%$ & $1,6 \%$ & $7,5 \%$ \\
\hline$<1.500$ & $91 \%$ & $80 \%$ & $1,5 \%$ & $6,8 \%$ \\
\hline Total & $92 \%$ & $85 \%$ & $1,2 \%$ & $6,9 \%$ \\
\hline
\end{tabular}

En la siguiente tabla podemos observar un poderoso indicio de irreligiosidad tratándose de la obligación anual de confesión y comunión del catolicismo en Pascua. Vemos como soslayan el precepto cuatro de cada diez mujeres a partir de un reducido conjunto de parroquias sobre las que hemos obtenido datos cuantitativos. 
Mundo, demonio y carne. Proceso de secularización, feminización de la religión y... 279

\begin{tabular}{|l|c|c|c|c|}
\hline \multicolumn{5}{|c}{ INDICIOS DE IRRELIGIOSIDAD POR GÉNERO } \\
\hline Parroquia & $\begin{array}{c}\text { Incumplimiento } \\
\text { pascual hombres }\end{array}$ & $\begin{array}{c}\text { Incumplimiento } \\
\text { pascual mujeres }\end{array}$ & TOTAL & $\begin{array}{c}\% \\
\text { mujeres }\end{array}$ \\
\hline Alcover & 950 & 330 & 1.280 & $26 \%$ \\
\hline Alió & 130 & 35 & 165 & $21 \%$ \\
\hline Botarell & 49 & 4 & 53 & $8 \%$ \\
\hline Cambrils (San Pedro) & 299 & 132 & 431 & $31 \%$ \\
\hline Cambrils (Santa María) & 72 & 30 & 102 & $29 \%$ \\
\hline Catllar, El & 290 & 120 & 410 & $29 \%$ \\
\hline Constantí & 360 & 110 & 470 & $23 \%$ \\
\hline Montbrió & 181 & 55 & 236 & $23 \%$ \\
\hline Morell, El & 300 & 190 & 490 & $39 \%$ \\
\hline Pont d'Armentera, El & 335 & 78 & 413 & $19 \%$ \\
\hline Reus (San Francisco) & 840 & 907 & 1.747 & $52 \%$ \\
\hline Reus (San Juan Bautista) & 650 & 1.600 & 2.250 & $71 \%$ \\
\hline Riudoms & 520 & 120 & 640 & $19 \%$ \\
\hline Roda de Bará & 68 & 12 & 80 & $15 \%$ \\
\hline Selva del Camp, La & 215 & 20 & 235 & $9 \%$ \\
\hline $\begin{array}{l}\text { Tarragona (San Juan } \\
\text { Bautista) }\end{array}$ & 2.000 & 1.580 & 3.580 & $44 \%$ \\
\hline Valls (Madre de Dios del & 740 & 60 & 800 & $8 \%$ \\
\hline Carmen) & 1.450 & 520 & 1.285 & $40 \%$ \\
\hline Valls (San António Abad) & 388 & 142 & 530 & $27 \%$ \\
\hline Valls (San Juan Bautista) & 10.602 & 6.895 & 17.497 & $39 \%$ \\
\hline Vinaixa & & & 2.300 & $37 \%$ \\
\hline Total & & & & \\
\hline
\end{tabular}

Fuente: AHAT. Estadística Diocesana, 1932. Elaboración propia.

\begin{tabular}{|l|c|c|c|c|}
\hline \multicolumn{5}{|c|}{ INCUMPLIMIENTO PASCUAL DE LAS MUJERES Y HABITAT } \\
\hline $\begin{array}{c}\text { Tamaño de la } \\
\text { parroquia }\end{array}$ & $\begin{array}{c}\text { Incumplimiento } \\
\text { pascual hombres }\end{array}$ & $\begin{array}{c}\text { Incumplimiento } \\
\text { pascual mujeres }\end{array}$ & TOTAL & $\begin{array}{c}\% \\
\text { mujeres }\end{array}$ \\
\hline$>5.000$ & 4.940 & 4.937 & 9.877 & $50 \%$ \\
\hline$<1500$ & 1.352 & 436 & 1.788 & $24 \%$ \\
\hline 1500 a 5000 & 4.310 & 1.522 & 5.832 & $26 \%$ \\
\hline Total & 10.602 & 6.895 & 17.497 & $39 \%$ \\
\hline
\end{tabular}

Feminismo/s 28, diciembre 2016, pp. 269-292 
La presentación estadística de los datos proporcionados por la muestra de la encuesta diocesana de Tarragona correspondiente a 1932 indican algunas conclusiones relevantes, como el distanciamiento de las prácticas de observancia de mujeres en un 39\% generalizado, aunque existen diferencias notables atendiendo a la tipología parroquial; así las de tipo urbano (Tarragona, Reus, Valls) presentan más equilibrio de género que las rurales, estableciéndose una correlación positiva entre ruralidad y feminización de la religión. Las mujeres en conjunto representan el 39\% del incumplimiento pascual, más notable en las ciudades aunque con excepciones significativas en Alcover, Pont d'Armentera (núcleo protestante), el barrio de pescadores de Cambrils o un pequeño pueblo como Alió. La investigación en microhistoria ha mostrado la relevancia de las rupturas comunitarias derivada de la organización socialista de tipo republicano, laico, que desafiaba el fuerte sentido de comunidad en el cual la religión desempeñaba un papel esencial. En el ámbito urbano parece claro que el apego de la burguesía a la Iglesia estaba vinculado a una vaga ideología política que consideraba la religión como un baluarte del orden social. En estas circunstancias, había pocas posibilidades de que la Iglesia formulara una estrategia que trascendiese las divisiones de clase. De hecho, ocurrió lo contrario (Callahan 202).

El triunfo del liberalismo y la aparición de una sociedad más secularizada en el siglo XIX impulsaron al clero hacia un convencimiento obsesivo de que había que tomar medidas enérgicas para contener «el diluvio ciego de la lujuria», ya en el cambio de siglo los sínodos prestaron mucha atención a la regulación de la moralidad sexual, con la condena drástica del adulterio y de los considerados vicios sexuales. Las amenazas para la moralidad solo se resolverían con el castigo y severas amonestaciones, así a los que cometían público adulterio y a los que vivían en concubinato se les debían negar los sacramentos. Se dijo a los sacerdotes que procurasen «apartar a sus ovejas de ciertos lugares de perdición, en donde naufragan con harta frecuencia las virtudes más sólidas y fervorosas». Se advirtió a los padres de las zonas rurales que retuvieran a sus hijos en casa por la noche y jamás les permitieran quedarse a solas con sus futuros esposos. Se exhortó a las mujeres a practicar «la modestia cristiana en el vestir» (Callahan 207); la Iglesia definitivamente ya no disponía de los instrumentos de control de los añorados tiempos de la alianza entre el Trono y el Altar que en una formulación para el siglo veinte y después de una guerra civil, calificada de cruzada religiosa, impuso el nacionalcatolicismo español en su empeño recristianizador que comportó una profunda redefinición de la feminidad. 
La Estadística diocesana de 1932 dedica el capítulo XXI a «Moralidad» en la certidumbre que las costumbres tradicionales sufrían impactos amenazantes en los modos de vida; así los párrocos dan cuenta de los cambios en las formas del ocio, satanizando la existencia de moda indecente (Alió; Alforja) por «cómo visten algunas doncellas» en una explícita manifestación del control del cuerpo femenino. En este mismo sentido se destaca en San Pedro de Cambrils un par de casos en que se «ha usado el matrimonio antes de haberlo contraído», o en Pont d'Armentera la «deshonestidad entre los jóvenes, por la noche de paseo», o en Riudoms sobre «fugas de algunos jóvenes para ir con sus novias». En San Juan de Reus se menciona el «vicio de lujuria por las modas contra las que se emplea la Liga de la Modestia». La histórica obsesión de la Iglesia por la sexualidad se normativizó en los mismos años que los párrocos cumplimentaban la encuesta, cuando en 1930 Pio XI (1922-1939) publicó la encíclica Casti connubii sobre la santidad del matrimonio, coherente con el patriarcado legitimado por el catolicismo. Así, las funciones que le van a ser atribuidas a la sexualidad y, en consecuencia, a las mujeres, pues somos a la vez metáfora y su metonimia, lo que la simboliza y aquello que la provoca (Amorós 251) en un dique de contención de lo que se intuía como, en palabras de Marcuse, «la» mujer va a pasar de «suelo ontológico» a plataforma emancipatoria, dadas las potencialidades subversivas de la liberación del deseo frente al principio del logro que preside el funcionamiento del orden capitalista (Amorós 252).

La obsesión de la Iglesia con los placeres mundanos y la práctica del rigorismo católico se resumen para el caso de la diócesis de Tarragona en el capítulo de la encuesta dedicado a «Moralidad» que enfatiza la existencia de espectáculos con «menoscabo a la moralidad» en la parroquia, que en la mayor parte de las parroquias consiste en la existencia de bailes, teatro y cine. En El Catllar, el párroco afirma que es la Sociedad Agrícola quién anima y organiza el baile y el cine. La confrontación sobre los espacios de sociabilidad recreativa será motivo de politización del hecho religioso durante la II República. En definitiva, los párrocos se muestran a la defensiva, conscientes del debilitamiento de unas tradiciones que mantenían acompasada la vida de todos y todas al ritmo que marcaba la religión, que en el marco de nuevas libertades en la «primavera» republicana sacaba a la luz un substrato laico cierto, aunque semioculto hasta entonces por la coerción (Rivera y de la Fuente 99).

En la tríada «mundo, demonio y carne», los tres enemigos del alma, el baile ocupa un lugar específico en tanto que manifestación de corrupción moral; así en San Francisco de Reus que «hay baile todo el año, se emplean los medios posibles para desterrarlo habiendo fundado una asociación católica de obreros con quinientas jóvenes obreras», en San Juan Bautista de Reus se indica que 
se ha creado una «escuela dominical para apartar a las jóvenes del baile y de espectáculos inmorales». El laicismo republicano se manifiesta como causa de la desafección a los preceptos. Así, en el Carmen de Valls el párroco indica que «hay bailes en la Sociedad Agrícola dónde antes se respetaba la Cuaresma, pero desde que impera el nuevo régimen se baila todas las épocas del año, si bien debido a la predicación y confesionario, son pocas las jóvenes que asisten durante el tiempo cuaresmal». El baile fue objeto de una intensa acción pastoral ya que «Todo baile en el que se ejecutan abrazos o contactos gravemente condenados por el sexto mandamiento es gravemente inmoral» como se sostenía en una publicación promovida por la Acción Católica de Barcelona en 1951.

\section{LAICIDAD EN LA SEGUNDA REPÚBLICA}

El cambio de régimen iniciado el 14 de abril de 1931 constituye una seria amenaza, según la Iglesia, al fomentar la secularización y crear condiciones de posibilidad para un cambio social profundo en los papeles de género, articulado en la modernidad sobre unas relaciones de experiencia entre hombres y mujeres en base a un imaginario legitimador de la dominación simbólica patriarcal.

La denominada «cuestión religiosa» tensionará la vida de las parroquias y socializará los conflictos Iglesia-Estado, debido a la aparición de múltiples «litigios de frontera». Según García Jordán, hay tres momentos en la relación de la Iglesia catalana en el primer bienio republicano: un primero de posibilismo para conseguir mantener los privilegios combinándolo con movilización para el ideario durante el debate del texto constitucional; un segundo, después del 9 de diciembre de 1931, de constitución del frente católico en contra de la ley de confesiones; y un tercero, de acceso de los «católicos» al gobierno central. Es la primera vez que España abandona el estado teocrático en pro de una secularización completa. La situación se agrava después de los incendios de iglesias en mayo, y el 3 de junio se hace pública la carta colectiva de los obispos. La reacción más importante de la Iglesia ante la política laicista fue la pastoral colectiva de enero de 1932. La ley de confesiones y congregaciones se plantea como culminación del ideario republicano laicista. Los artículos 26 y 27 daban a la Constitución el tono más agresivamente laico de su historia (Duch 1994, 127).

La ley, aprobada por 278 votos a favor y 50 en contra, tenía que afectar a la comunidad de religiosas de provincia, que en 1930 era de 1799 personas: 387 religiosos y 1.412 religiosas. Existen en la provincia siete comunidades religiosas, dos de las cuales dedicadas a la enseñanza, y 16 órdenes religiosas femeninas, dedicados 7 a la enseñanza, 5 a beneficencia y 2 contemplativos. En la ciudad de Tarragona había 7.48 comunidades por cada diez mil habitantes, 
mientras que a nivel español era de 3.58; en relación al número de religiosos, en Tarragona capital era de 148.63 por diez mil mientras que la mediana española era de 71.10. Existen en la capital 90 religiosos masculinos y 367 monjas, un total de 23 comunidades y 547 clérigos (Duch 1997, 128). Entre 1888 y 1927 los monasterios femeninos en España se incrementaron de 1.027 a 3.728 mientras que los masculinos pasaron de 161 a 970. La expansión de las órdenes femeninas se debe al reconocimiento de la Iglesia de la importancia de la enseñanza y en la expansión de actividades caritativas como medio para aumentar su influencia (Callahan 181).

Las manifestaciones del conflicto religioso durante la Segunda República en los municipios de Tarragona evidenciaron la polarización social ante la política laicista mediante la movilización de la jerarquía y del asociacionismo católico, especialmente femenino. La mayor concentración del clero se encuentra en el Alt Camp, la comarca con menos población y con una proporción de un cura por cada 355 habitantes; la ciudad de Valls, como hemos visto en la tabla de observancia religiosa muestra actitudes reactivas a preeminencia social del clero. Las comarcas de Tarragona y Reus se sitúan en torno a los 860 habitantes por cada clérigo, mientras que en las respectivas ciudades asciende a 1.300. La densidad asociativa católica es importante con municipios con numerosas cofradías, hermandades y asociaciones: La Catedral (11), el Morell (7), en sólo 13 parroquias de la comarca de Tarragona se contabilizan 5.398 afiliados. En el Baix Camp el total de afiliados son 23.745 en 15 parroquias analizadas. En las ciudad de Reus destacan San Juan (1.700) y San Pedro (6.339). La red local y diocesana se manifiesta poderosa en número de efectivos cotizantes aunque menos dinámica, a excepción de las ceremonias de semana santa o de los propios rituales anuales, de lo que la jerarquía hubiese deseado y socializado para estimular la movilización católica ante las políticas laicistas de la II República mediante el periódico católico publicado en Tarragona, La Cruz (1901-1936).

En la información recogida sobre los bautismos destaca el caso de El Pont d'Armentera, con hasta 3 infantes no bautizados, muy significativo por tratarse de un núcleo rural donde existe un núcleo protestante importante. En el Catllar (2) se hace referencia al «sectarismo creciente de la República» y a una «pugna entre propietarios y aparceros desde el advenimiento de la República, dedicándose éstos aparceros a hacer propaganda para que no haya bautizos», ejemplo de una conexión estricta entre el conflicto social agrario y el anticlericalismo; en la parroquia del Carmen de Valls se hace referencia a un niño y una niña debido a que «sus padres viven amancebados [...], son de ideas perversas y no quieren oír de religión», las gestiones de las «buenas personas para que se 
bautice a sus hijos resultan infructuosas». En la Riba se informa de que hay personas no bautizadas, «unos por sectarismo y otros por protestantes».

Un capítulo de la Estadística cursada a los párrocos en 1932 por la Vicaría general del Arzobispado pretende conocer la existencia de comités o personas que trabajen con la finalidad de que no se hagan bautizos. Las parroquias en las que existan núcleos protestantes (Pont d'Armentera) o republicanismo militante se habían atrevido a desafiar el ritual católico en los ciclos de vida bajo el estímulo que proporcionó la política laicista del gobierno español. Así, en los municipios de Alió, El Catllar y la Parroquia de San Juan Bautista de Tarragona hay personas que independientemente de ningún comité trabajan con dicha finalidad, especificándose en El Morell que aun habiendo personas que trabajen con la finalidad indicada «aún no lo han conseguido, pero lo conseguirán».

La presencia de congregaciones religiosas prolifera también en núcleos significativos de la propaganda laica, como es el caso de Barberà de la Conca. Este municipio, con importante organización socialista desde las últimas décadas del siglo XIX, vivió el conflicto religioso en 1931 de manera intensiva como así describe su párroco. Los hechos remiten a que el 19 de abril de 1931 se produjo una crisis en relación a la primera comunión: «La propaganda antirreligiosa provocó que todo y con tener la ropa preparada, el párroco las estampas, dejan de hacerla». Y desde entonces ningún niño o niña de la Sociedad ${ }^{4}$ han pisado la iglesia y ay de la niña que viniese que le hacen el vacío los y las demás».

En mayo de 1931 prosigue su relato el párroco de Barberà de la Conca «las jóvenes se dieron de baja de la Asociación de Hijas de María y los hombres y las mujeres acordaron hacerlo todo por lo civil», así el 24 de mayo se produjo el primer nacimiento sin bautizo católico y el 28 del mismo mes el primer entierro civil, mientras que en agosto y octubre se formalizan los primeros «concubinatos». Otros aspectos del combate laico son percibidos por el párroco cuando afirma que el $25 \%$ de la población del pueblo no pertenece a la Sociedad, «los hombres tampoco tienen fe, sólo que son unos sectarios», mientras que las mujeres «generalmente cumplen los preceptos dominical y pascual. Las jóvenes también siguen a sus madres».

El párroco, en su largo informe recogido en el apéndice de la encuesta, sostiene que «desde que ha cambiado el régimen serian contraproducentes todas las gestiones. Se ha formado la Liga Laica y hay personas que realizan propaganda para que no se bauticen, y las madres son las primeras en no quererlo». Una de las explicaciones del anticlericalismo es de orden socioeconómico, a la cual se adhiere el párroco de Barberà cuando afirma que «desde hace sesenta

4. Según el párroco pertenecía a la Sociedad el $75 \%$ de la población. 
años los propietarios tenían muy sujetos y como esclavizados a los aparceros y jornaleros (...) los dueños cumplirían más o menos con la Iglesia y hacían oídos de mercader a las justas demandas, así empezaron a concebir odio a la Iglesia como favorecedora de los ricos y explotadora de los pobres». Un conflicto social que culmina con la creación en 1894 de la primera cooperativa agraria creada desde abajo, de orientación socialista, en Cataluña (Fuguet y Mayayo). El párroco, Francisco Mercadé, relata cómo levantaron un edificio llamado «La Casa» en 1912 con dependencias de café y baile y escuela con un maestro laico «que continúa hasta la fecha [...] con el resultado que han crecido contra Dios. Hasta la proclamación de la República guardaban algunas formas de nuestra religión» como matrimonios o enterramientos a pesar de que eran «herejes en su mayor parte y ateos todos».

En las políticas laicizantes sobre los entierros civiles es significativo que, aunque hubiere muchas quejas de los párrocos sobre el creciente laicismo y el ya de por sí laicismo político que nace con el régimen de la República, entre todas las parroquias de la muestra sólo suman 25 casos de entierros civiles. Sobresale el caso en el Carmen de Valls, dónde se indica que se intentó advertir a las hijas del difunto pero que «las hijas comunistas no oyeron al párroco». La explícita declaración sobre voluntad de enterramiento civil a la que la Iglesia respondió a la secularización de cementerios motiva una intensa campaña en las parroquias, casi un «recuento de efectivos». Así, en Catllar se indica que «no han firmado por sectarismo, particularmente las mujeres por miedo a familiares y amigos y unos por indolencia», en El Morell muchos han firmado sin entregar el duplicado, ignorándose el motivo. El miedo también es causa de doscientas personas que dejan de firmar la declaración de voluntad de funeral religioso en Pont d'Armentera y Porrera, núcleos más secularizados o de laicismo excluyente de nueva gestación.

La ley del divorcio y la regulación del matrimonio civil modificaron los ítems de la encuesta diocesana para documentar el desafío laicista. Así se contabilizan los matrimonios civiles desde la proclamación de la República no relevantes en proporción a los católicos ya que se registran solamente 13 matrimonios civiles en los municipios de la muestra cuando se realizaban, según los párrocos, hasta 573.7 matrimonios anuales de media. El caso más destacable de la muestra se da en el Pont d'Armentera, importante núcleo protestante, dónde de un promedio anual de 6 matrimonios, existen 4 parejas casadas por lo civil.

Los párrocos también informan sobre aquellas personas que viven sin estar casadas por el rito católico; en la mayoría de las parroquias no se dan casos de personas que vivan en concubinato, pero sí se informa que las hubiere en La Riba y en el Carmen de Valls (2) o en San Juan Bautista de Valls (4 o 
5). En la parroquia de la Santísima Trinidad de Tarragona se informa de que «hay casos, imposible de determinar por falta de tiempo, algunos tienen hijos bautizados». La actitud expresada por los párrocos se refleja en expresiones defensivas como el caso de Constantí, dónde el párroco hubiere usado la huelga para que se hagan matrimonios canónicos; en Morell se indica que «es inútil toda diligencia, son unos miserables, no han hecho caso de lo que se les ha dicho, todo lo desprecian»y, en el Carmen de Valls también se indica que es inútil toda diligencia a emplear.

La estadística intenta documentar el número de personas divorciadas que viven en cada una de las parroquias, dándose cifras muy bajas, con una persona en San Pedro de Cambrils o dos en Alforja o San Francisco de Reus, 4 del Carmen de Valls, aunque las cifras más elevadas se dan en núcleos rurales como Riudoms (5) o Constantí (6). La Iglesia era consciente que la regulación del matrimonio como uno de los derechos de ciudadanía que la República promovió podría, simbólicamente, desafiar la costumbre y, a medio plazo, normalizar el pluralismo ideológico; por todo ello se pretende conocer la existencia de comités o personas que trabajen contra el matrimonio canónico en pos del matrimonio civil, que los párrocos desconocen a excepción de Alió y Morell, San Juan Bautista de Tarragona y Alcover, práctica que se personaliza en Marta Domingo.

Entre los «vicios contra la santidad del matrimonio», se menciona reiteradamente el onanismo y el maltusianismo. En Porrera se dice que «las mujeres son las más sensibles» ante lo que el párroco señala que «veo difícil el remedio a un mal endémico». En Cataluña se produjo un notable descenso de la natalidad situándose el número de hijos por mujer de 2,6 a 1,9 entre 1922 y 1935 (Nash y Borderías 163). Prácticas de control de natalidad que los párrocos recogían en sus informes y que reflejan un reajuste de valores culturales con la aparición de una nueva moral sexual no basada en los preceptos católicos como cuando constatan la falta de recato en el comportamiento público y particularmente en las ropas de las mujeres (Lannon 1999, 65), hecho que fue objeto en 1926 de una declaración colectiva de la Junta de Reverendísimos Metropolitanos, constituida tres años antes.

\section{ESPIRITUALIDAD Y SOCIABILISMO FEMENINO CATÓLICO}

En una España eminentemente católica como la de finales del XIX y primeras décadas del XX se desarrollará una espiritualidad caracterizada por las concepciones morales del eterno femenino que exigían a las mujeres una vida religiosa de renuncia, resignación, silencio, evasión, enemistad con la vida, desprecio del propio cuerpo y negación del placer (Tamayo 134). El número 
de religiosas en España se dobló entre 1860 y el cambio de siglo llegando a cuarenta mil y creció hasta sesenta mil en 1930 cuando el total de religiosas, en su mayoría en comunidades activas, era tres veces superior al de religiosos y superior a la suma de religiosos y sacerdotes diocesanos. Las monjas aparecían como servidoras de Dios, modelos de vida abnegada a imitar por las mujeres.

En el estado de la cuestión sobre la «moralidad», la Estadística diocesana enfatiza si «ocurren en la parroquia escándalos graves», «los vicios dominantes en la misma y qué remedios se aplican para su extinción o disminución y cuáles podrían con mayor eficacia adoptarse», la celebración de «bailes en todas las épocas del año y si hay cines, varietés u otros espectáculos con menoscabo de la moralidad, y qué medios se emplean para contrarrestar sus efectos», así como «si se ha notado el respeto debido a la Cuaresma en las diversiones o se ha faltado respeto de este particular y desde que fecha». Transcurridos unos meses desde la proclamación de la II República, los párrocos describen cambios secularizadores generalizados como en San Juan de Reus «desde que la autoridad civil ha quitado las fiestas de precepto». Es generalizada la opinión sobre la prevalencia de comportamientos, menos escandalosos pero más endémicos, entre la población, como la blasfemia, el juego y la profanación de días festivos y otros de nuevo tipo como el «sectarismo republicano» (El Catllar), inmoralidad conyugal, los deseos de diversiones y la indiferencia religiosa (Morell) o la falta de asistencia a misa. En Riudoms se señala la inmodestia de vestir y en Roda de Berá se habla «de envidias y rencores en hombres y mujeres»; y uso de la murmuración y la lujuria en Vinaixa, dónde el párroco da consejo avisando y no consigue nada particularmente desde «abril del pasado año 1931». En San Pedro de Reus se informa que «si se saben en concreto se aplican los remedios convenientes» que pasan por la predicación, que en Constantí se suma al «celo de los celadores del Apostolado de la Oración».

El calendario católico será objeto de debate político en el plano local sobre la celebración de procesiones especialmente, como así también sucede con el respeto a la Cuaresma que la Iglesia propugnaba. En las treinta parroquias analizadas se muestra que en seis de ellas no se realizan espectáculos mientras «se ve algo de respeto» en otras seis. Ante una cuestión central en las relaciones de género, cortejo y aparejamiento como era el baile en las comunidades rurales y los barrios urbanos de los años treinta, observamos que en el 60\% de las parroquias en 1932 no se respetaba la suspensión del baile dominical durante la cuaresma. Por el contrario, en dieciocho de las parroquias se indica que no se respeta: en Aleixar «sí se respeta en baile pero no en cine»; en Pont d'Armentera se indica que se respetaba hasta la República; en la Sangre de Reus que «no respetan nada»; en San Pedro de Reus «se paran los bailes pero no 
los cines» o en Riudoms que se intenta contrarrestar los espectáculos de todo tipo con «Cultura de la dona», obra social católica (Duch y Palau); tampoco se respeta en Vinaixa: «este año ha sido el primero que no se ha respetado, aún con los avisos del párroco hubo baile».

Lo privado se convierte en una nueva arma ideológica en la lucha por una sociedad secularizada liberada de dominación religiosa. Determinados ritos sociales, como el registro de los hijos, los matrimonios y los entierros civiles, constituyen testimonios de una cultura laica alternativa a la católica, en lo que Moreno considera como «laicismo militante». Las prácticas de vida, privadas y públicas abren espacios a la incorporación de las mujeres a los derechos y libertades. Dichas ceremonias permiten reforzar la identidad colectiva de estos grupos, que se transmiten a las generaciones futuras, tarea en que se reserva una importante función a las mujeres» (Moreno 69).

En el Epígrafe XXVI la estadística incluye información sobre Obras Sociales «informadas del espíritu de la Iglesia Católica»; en las parroquias urbanas (Reus) encontramos la Biblioteca de Buenas Lecturas y la Liga Espiritual contra la Blasfemia, el Centro Católico o asociaciones como Caridad Cristiana de Señoras y Mutual Femenina de Misericordia. En Tarragona, Acción Popular Católica (600 asociados) o Acción Católica de la Mujer, creada en 1920 con 551 asociadas o en Valls la agrupación político-social tradicionalista y la Mutua de Propietarios, Hermandades de Socorros Mutuos, Asociación de Padres de Familia. El cambio de régimen comportó que algunas de estas obras se fortalecieran mientras que otras dejaron de actuar, como la Cofradía de San Vicente de Paúl (Alforja), un municipio dónde el párroco informa de la existencia de una «Sociedad comunista con 20 socios hostiles a la Iglesia», como así también sucedió en Alió (509 habitantes) dónde según el párroco «casi todo el pueblo pertenece a las sociedades socialistas y comunistas. Se ataca a la religión y se insulta a sus ministros». En Barberà la respuesta católica al laicismo militante consistió también en la creación de Cívica Femenina Cultural, «Dios quiera en el próximo quinquenio pueda desarrollarse y dar óptimos frutos» En algunas parroquias se creó la «Cultura de la dona», inspirada en el «Institut de Cultura i Biblioteca Popular de la Dona» creada en Barcelona (Duch 2015a). Al desafío de la sociabilidad laica en muchas parroquias que impugnaba las costumbres tradicionales en los ritos de paso vitales se respondió, como vemos, con el reforzamiento del tejido asociativo católico formal.

Pio XI, «el Papa del catecismo», había dado un gran impulso a la catequesis a través de la encíclica Acerbo Nimis (1905) en el convencimiento de que ante las persecuciones y las malas costumbres el único remedio era la enseñanza de la doctrina cristiana; una «panacea que ignoraba una vez más el devenir de 
las cosas, en suma, la modernidad. El hecho es que la catequesis funcionaba con notable eficacia incluso en las zonas más difíciles. Pero entre la niñez y la adolescencia, los jóvenes más que las jóvenes se perdían para la Iglesia en gran número» (Rivera y de la Fuente 97).

Uno de los ítems de la Estadística se refiere a las relaciones de la parroquia con los centros escolares existentes en los municipios. El clero pensaba que la complicada y conflictiva vida social de las primeras décadas del siglo XX en España tenía como causa directa la influencia negativa de la prensa y de la educación (Crovetto 287). Otro aspecto pretendía describir la enseñanza del catecismo -frecuencia, duración, texto, metodología y resultados-. Así en el epígrafe XXVIII de la estadística de 1932 se pretendía recoger el estado de la cuestión sobre la enseñanza del Catecismo en las escuelas, cuya obligación se reguló en 1838, con la implicación de maestros y maestras en el culto católico.

Con motivo de las medidas laicistas del gobierno de la Segunda República se prohibió la enseñanza del catecismo, en respuesta a una permanente presencia de los sacerdotes en las escuelas públicas que las visitaban con una frecuencia semanal, así como es generalizada la práctica de que maestros y maestras acompañaran dos veces al año a los niños y niñas. La estadística aporta exhaustiva información sobre la identidad de maestros y maestras, así como de las relaciones «cordiales y frecuentes con el párroco» o «frías y corteses» en otros casos. En San Pedro de Reus se daba tres horas a la semana de catecismo más visita semanal, «mejor relación con los maestros de las escuelas privadas, los de las públicas fríos». En Valls se dan uno o dos días a la semana durante una hora el catecismo y visitas «cinco o seis al año que no eran muy del agrado de los maestros, desde el nuevo régimen no se ha hecho ninguna visita». La anticipación a la legislación sobre congregaciones religiosas se presentaba a los párrocos

El dimorfismo sexual se aprecia en un mayor abstencionismo de los hombres a las ceremonias religiosas como una característica de su comportamiento; una masculinidad alejada de las prácticas y las devociones congruentes con la feminidad. Así, en la parroquia de La Sangre de Reus había protestantes y espiritistas, «unas ochenta personas que propagan sus errores sin resultado», una afirmación compatible con anotar la existencia de núcleos activos de disensión al catolicismo.

«La atribución progresiva de mayor religiosidad a las mujeres (algo que comparten, desde el último tercio del siglo XIX, católicos y liberales) sería precisamente un producto de la integración de la diferenciación sexual como un rasgo relevante de la identidad por parte de un catolicismo que, medio 
siglo antes, había exaltado el sentimiento católico de ambos sexos frente a la modernidad» (Blasco 130).

La feminización de la religión creó las posibilidades discursivas para la movilización sociopolítica de las mujeres católicas en la primera mitad del siglo $\mathrm{XX}$, para la activa respuesta femenina a la secularización. No ha sido objeto de este análisis el movimiento católico femenino aunque me inclino a pensar que «la Iglesia aprovechó el potencial femenino para movilizar a las mujeres, que son presentadas como instrumentos del clero, de una institución patriarcal cuyas normas habían internalizado» (Blasco 131). Así, si bien la jerarquía católica propulsó y alentó las organizaciones femeninas, éstas se basaron en las motivaciones de sus protagonistas en términos de acceso a lo público, de oferta de otras opciones alternativas a las socialmente asignadas a las mujeres de entonces en reconocimiento social y de aprendizaje de la práctica de la participación pública, aunque el resultado final fuese una emancipación parcial e inacabada, ya que no impugnaron el modelo de las esferas separadas ni la exclusión de la ciudadanía.

\section{REFERENCIAS BIBLIOGRÁFICAS}

Alonso, Gregorio. «La secularización de las sociedades europeas». Historia Social 46 (2003): 113-157.

Amorós, Celia. Tiempo de feminismo. Sobre feminismo, proyecto ilustrado y postmodernidad. Feminismos. Madrid: Cátedra, 1997.

Arce Pinedo, Rebeca. Dios, Patria y Hogar. La construcción social de la mujer espanola por el catolicismo y las derechas en el primer tercio del siglo XX. Santander: Publican. Ediciones de la Universidad de Cantabria, 2008.

Blasco, Inmaculada. Paradojas de la ortodoxia: política de masas y militancia católica femenina en España (1919-1938). Zaragoza: Prensas Universitarias de Zaragoza, 2003.

Blasco, Inmaculada. «Género y religión: de la feminización de la religión a la movilización católica femenina. Una revisión crítica». Historia Social 53 (2005 a): 119-136.

Blasco, Inmaculada. «Dones i activisme catòlic: l’Acción Católica de la Mujer entre 1919 y 1950». Recerques 51 (2005 b): 115-139.

Blasco, Inmaculada. «Ciudadanía femenina y militancia católica en la España de los años veinte: el feminismo católico». Religión y política en la España contemporánea. Coord. Carolyn P. Boyd. Madrid: Centro de Estudios Políticos y Constitucionales (CEPC), 2007, 187-208.

Callahan, William J. La Iglesia católica en España (1875-2002). Barcelona: Crítica, 2002. 
Crovetto, Fernando. «Secularización y clero en la Archidiócesis de Zaragoza durante el primer tercio del siglo XX: la percepción de Juan Soldevila y Romero». SetD 5 (2011): 285-308.

De la Cueva, Julio. «Políticas laicistas y movilización anticlerical durante la Segunda República y la Guerra Civil». Secularización y laicismo en la España contemporánea. Ed. Manuel Suarez Cortina. Santander: Sociedad Menéndez Pelayo, 2001, 255-280.

De la Cueva Merino, Julio y Feliciano Montero (eds.). La secularización conflictiva, España (1898-1931). Madrid: Biblioteca Nueva, 2007.

Delgado, Manuel. La ira sagrada. Anticlericalismo, iconoclastia y antirritualismo en la España contemporánea. Barcelona: Humanidades, 1992.

Díaz-Salazar, Rafael. El capital simbólico. Estructura social, política y religión en España. Madrid: HOAC, 1988.

Duch, Montserrat. República, reforma i crisi. El Camp de Tarragona (1931-1936). Tarragona: El Mèdol, 1994.

Duch, Montserrat. «Actituds populars i control social. Les parròquies del bisbat de Tarragona (1927)». AAVV. Els temps sota control. Tarragona: Diputació de Tarragona, 1997, 261-271.

Duch, Montserrat y Montserrat Palau. «La socialización de los saberes femeninos: el Instituto de cultura y biblioteca popular para la mujer, Barcelona (1900-1936)». Historia Social 82 (2015a): 133-147.

Duch, Montserrat. «El género de la sociabilidad europea contemporánea: notas para su estudio». Sociabilidades en la Historia. Coords. Santiago Castillo y Montserrat Duch. Madrid: Catarata, 2015b, 115-132.

Eliade, Mircea. The Encyclopedia of Religion. Tomo 13. Londres-Nueva York: Macmillan, 1987.

Figuerola, Jordi. «Movimiento religioso, agitación social y movilización política». Historia Social 35 (1999): 65-80.

Fuguet, Joan y Andreu Mayayo. El primer celler cooperatiu de Catalunya, centenari de Barberà de la societat de Barberà de la Conca: 1894-1994, Barcelona: Generalitat de Catalunya, Departament d'Agricultura, 1994.

Garcia, Amelia. Ideología y práctica de la acción social catolica femenina (Cataluña, 1900-1930). Málaga: Universidad de Málaga, Colección Atenea. 2007.

García, Pilar. Els catòlics catalans i la Segona República. Montserrat. Publicacions de l'Abadia, 1986.

Gibson, Ralph. A social history of French Catholicism, 1789-1914. Londres: Routledge, 1989.

Langlois, Claude. «Catholicisme au féminin ou feminisation du catholicisme? Délemitier ou definer un nouveau champ de recherché en histoire et en sociologie». Annuaire de l'École Practique des Hautes Etudes 102 (1994): 379-385. 
Lannon, Frances. Privilegio, persecución y profecia. La Iglesia Católica en España, 1875-1975. Madrid: Alianza, 1990.

Lannon, Frances. «Los cuerpos de las mujeres y el cuerpo político católico: autoridades e identidades en conflicto en España durante las décadas de 1920 y 1930». Historia Social 35 (1999): 65-80.

Luna, Joana y Elisenda Macià. «L'associacionisme femení; catolicisme social, catalanisme i lleure». Més enllà del silenci: les dones a la historia de Catalunya. Ed. Mary Nash. Barcelona: Generalitat de Catalunya, 1988, 227-242.

Marramao, Giacomo. Poder y secularización. Barcelona: Península, 1989.

Mcmillan, James. «Religion and Gender in Modern France: Some Reflextions. Religion, Society, and Politics in France since 1789. Eds. Frank Tallet y Nicholas Atkin. Ohio: Hambledon Press, 1991, 55-66.

Minguez, Raúl. «Las múltiples caras de la Inmaculada: religión, género y nación en una proclamación dogmática (1854)». Ayer 96 (2014): 39-60.

Montalbán, Francisco J. Historia de la Iglesia Católica IV: Edad Moderna (16481963). La Iglesia en su lucha y relación con el laicismo. Madrid: Biblioteca de Autores Cristianos, 1963.

Moreno, Mónica. «Mujeres y sociabilidad laica (1875-1931)». Asparkia 17 (2006): 61-80.

Nash, Mary. «El neomaltusianismo anarquista y los conocimientos populares sobre el control de la natalidad en España» Presencia y protagonismo. Aspectos de la historia de la mujer. Ed. Mary Nash. Barcelona: Serbal, 1984, 307-340.

Nash, Mary y Cristina Borderías. «La presencia de la dona». L’època dels nous moviments socials 1900-1930, VIII: Història. Política, societat i cultura dels Països Catalans. Dir. Jordi Casassas. Barcelona: Fundació Enciclopèdia Catalana, 1995, 162-178.

P. Jereminas de las SS. Espinas. ¿Es inmoral el baile agarrado? Pamplona: Editorial Gómez, 1951.

Rivera, Antonio y Javier de la Fuente. «Modernidad y religión en la sociedad vasca de los años treinta». Historia Social 35 (1999): 81-100.

Salomón, P.: «Beatas sojuzgadas por el clero: la imagen de las mujeres en el discurso anticlerical en la España del primer tercio del siglo XX». Feminismo/s 2 (2003): 41-58.

Sanfeliu, Luz. Republicanas. Identidades de género en el blasquisme (1895-1910). Valencia: Universitat de Valencia. 2005.

Suárez, Manuel (ed.). Secularización y Laicismo en la España Contemporánea. Santander: Sociedad Menéndez Pelayo, 2001.

Tamayo, Juan José. Desde la heterodoxia. Reflexiones sobre laicismo, política y religión. Madrid: Ediciones del Laberinto, 2006.

Warner, M. Tú sola entre las mujeres. El mito y el culto de la Virgen María. Madrid: Taurus, 1991. 